\title{
Antibacterial and Antifungal Actuvity of Organic Solvent Extracts Of Knoxia Corymbosa
}

\author{
*R.Mrutyunjaya Rao $^{1}$ K.Ramakrishna ${ }^{2}$, K.PavaneeMounika ${ }^{3}$, M.Ravikumar ${ }^{4}$ \\ M.V.S.Murhy ${ }^{5}$ and G.Divya Ester ${ }^{6}$. \\ ${ }^{1 .}$ Department of $R \& D$ centre S.R.K.R. Engineering College, Bhimavaram. India. \\ 2, 4,5 Department of Chemistry and Botany V.S.M College, Ramachandrapuram. India. \\ ${ }^{3}$. Department of Microbiology, Dr.B.V.Raju institute of computer Education. India. \\ 5. Department of Biotechnology, Andhra University, Waltair. India.
}

\begin{abstract}
Objective: In this study the potency of antibacterial activities of crude organic solvent extracts ethyl acetate, dichloromethane, and methanol extracts of Knoxia corymbosa were tested on bacterial pathogens Escherichia coli, Klebsiella pneumonia, Staphylococcus aureus, Streptococcus pneumonia, Bacillus subtilis and the potency of antifungal activities of crude organic solvent extracts ethyl acetate and methanol extracts were tested on fungal pathogens Aspergillus niger and Candida albicans.
\end{abstract}

Key words: Anti-bacterial activity, Anti-fungal activity, Potato dextrose agar (PDA), Streptomycin sulphate.

\section{Introduction}

The ethno medical and ethno botanical uses of the plants are completely crude uses of plants parts like leaves, roots stem, bark etc. But the chemical analysis intended to find out to the chemical substances, which is responsible for the medicinal effect. So this is an interdisciplinary subject. A lot of work has been going on this way throughout the globe. In Andhra University a significant work has been going on. Ayurveda, the ancient healing system of India, flourished in the Vedic Era in India. According to historical facts, the classical texts of Ayurveda, Charaka Samhita and Sushruta Samhita were written around 1000B.C.The Ayurvedic Materia Medica includes 600 medicinal plants along with therapeutics. Herbs like turmeric, fenugreek, ginger, garlic and holy basil are integral part of Ayurvedic formulations. The formulations incorporate single herb or more than two herbs (poly-herbal formulations). Knoxia corymbosa is an erect perennial herb Family Rubeacea mostly 40$90 \mathrm{~cm}$ tall. Stems are little-branched, velvety. Leaves are narrow-lance shaped to ovate, mostly $2.5-8 \mathrm{~cm}$ long, 0.8-3.5 cm wide, tip pointed to long-pointed, base wedge-shaped to flat, margins with fine hairs. Both surfaces of the leaves are velvety, and the leaf-stalk is 3-10 mm long. Flowers are borne in a dense, cyme up to $4 \mathrm{~cm}$ long, carried on a $0.2-2.5 \mathrm{~cm}$ long stalk, at the end of branches. Flowers stalks are $0.5-1 \mathrm{~mm}$ long. Flowers are usually 1.5-2 mm long, purplish blue or rarely white. Anthers protrude out. Fruit is ellipsoid about $1.5-2 \mathrm{~mm}$ long, crowned by sepals, usually falling entire. Knoxia corymbosa is found in Indo-Himalaya region, peninsular India and Sri Lanka. Flowering: September-October. Knoxia corymbosa is assumed to containing some medicinal values because some authors reported that they isolated some chromone glycosides. Knoxia valerianoides is a Knoxia species from which an herbal medicine and $\beta$-sitosterol is one of its main components was isolated by Je-Chuan Ye etal. B-sitosterol is known to control cholesterol levels, reduce the activity of cancer cell, promote prostate gland health enhance immunity in the human body.

\section{Collection Of Plant Material:}

\section{Materials And Methods:}

Fresh plants of Knoxia corymbosa free from disease were collected from Y.Ramavaram of Addatheegala, virgin forests of Bison hills of East Godavari District Andhra Pradesh India. Location coordinates of Y.Ramavaram are $17.48330 \mathrm{~N}$ and 82.01670c. Plant identification was verified by M.Ravikumar of Department of Botany V.S.M college Ramachandrapuram. The plants were washed thoroughly 2-3 times with running water and finally once with sterile distilled water. The plant material was then air dried on sterile blotter under shade for 5 days and then powdered with the help of a blender.

\section{Solvent Extraction:}

$25 \mathrm{gm}$ of shade dried powder was filled in the thimble and extracted successively with Methanol, Ethyl acetate, Dichloromethane solvents in soxhlet extractor for 48 hours. The solvent extracts were concentrated under pressure and preserved at $4^{0} \mathrm{C}$ in an airtight bottle for further use. 


\section{Growth and Maintenance of Bacterial and Fungal Cultures for Antimicrobial studies:}

The lyophilized forms of different strains of microorganisms like Escherichia coli [MTCC-2126], Staphylococcus aureus [MTCC-3160], were obtained from the Microbial Type Culture Collection and Gene bank (MTCC),Chandigarh, India and the bacterial Strains Streptococcus faecalis [NCIM-2603] and Streptococcus pyogens ,Bacillus subtilis [NCIM-2655] were obtained from National Collection of Industrial Microorganisms (NCIM), Pune,India.

\section{Preparation Of Inoculum For Anti Microbial Studies:}

The Gram positive (Staphylococcus aureus, Staphylococcus pneumonia and Bacillus subtilis)and Gram negative(Escherichae coli and Klebsiella pneumonia) bacteria were precultured in Nutrient Broth over night in a Rotary shaker Incubator at 370c, the culture broth was centrifuged at 10,000 rpm for 5minutes, pellet was suspended in double distilled water and the cell density was standardized Spectrophotometrically(A610nm). The fungal inoculum for Aspergillus Niger was prepared from 5-10day old culture grown on Potato Dextrose Agar medium the petri dishes were flooded with $10 \mathrm{ml}$ of distilled water and the conidia were scroped with a sterial spatuala. The spore density of each fungus was adjusted with spectrophotometer (A $595 \mathrm{~nm}$ ) to obtain final concentration of approximately 105 spores per $\mathrm{ml}$

Method: Antibacterial activity of isolated crude organic solvent extracts ethyl acetate, dichloromethane and methanol extracts of Knoxia corymbosa was checked by agar well diffusion method.

\section{Anti Bacterial Activity Assay:}

The Gram positive bacteria Staphylococcus aureus, Staphylococcus pneumonia and Bacillus subtilis and Gram negative bacteria Escherichia coli and Klebsiella pneumonia were tested for their susceptibility to extracts of Knoxia corymbosa by disc diffusion method. Crude organic solvent extracts of Knoxia corymbosa were prepared for antimicrobial assays by reconstituting with the respective organic solvents. The test bacteria were seeded into Mueller Hinton agar medium Spread plate method10 $\mu 1$ (106cells $/ \mathrm{ml})$ with overnight grown cultures of Bacteria in Nutrient broth, The Filter paper discs $5 \mathrm{~mm}$ in diameter impregnated with $5 \mu \mathrm{g} / \mathrm{ml}-1$ of the crude organic solvent extracts were placed on test organism seeded plates were used for the antibacterial tests .Streptomycin sulphate $(10 \mu \mathrm{g} / \mathrm{ml}-1)$ was used as positive control and the organic solvents were used as negative control. The antibacterial assay plates in triplicates were incubated at $370 \mathrm{C}$ for $24 \mathrm{hrs}$. The diameters of the inhibition Zones were measured in $\mathrm{mm}$.

\section{Anti Fungal Activityassay:}

Aspergillus niger and Candida albicans were tested for their susceptibility to crude organic solvent extract of Knoxia corymbosa . The antifungal activity was tested by disc diffusion method The Potato Dextrose Agar plates were inoculated with each fungal culture (10 days old)by point inoculation. The filter paper discs ( $5 \mathrm{~mm}$ in diameter)impregnated with $5 \mu \mathrm{g} / \mathrm{ml}-1$ concentrations of the crude organic solvent extracts were placed on test organism seeded plates. The respective organic solvents were used to dissolve the extract and was completely evaporated before application on test organism seeded plates.A blank disc impregnated with the respective organic solvent followed by drying off was used as negative control and the fungicideNystatin $(10 \mu \mathrm{g} / \mathrm{ml}-1)$ was used as positive control.The activity was determined after $72 \mathrm{hrs}$ of incubation at $280 \mathrm{C}$.The diameters of the clear inhibition zones were measured in $\mathrm{mm}$.

\section{Results And Discussion:}

Ethyl acetate extract showed antibacterial activity against a total of five bacterial strains Escherichia coli, Klebsiella pneumonia, Staphylococcus aureus, Streptococcus pneumonia, Bacillus subtilis and and antifungal activity against a fungal species Aspergillus niger. dichloromethane extract doesn't show any antimicrobial and antifungal activity. Methanol extract showed antibacterial activity against three bacterila strains Staphylococcus aureus, Streptococcus pneumonia, Escherichia coli and antifungal activity againt Aspergillus niger.

Table 1: Antibacterial activity of crude organic solvent extracts of knoxia corymbosa $-5 \mu 1 / 50 \mu 1$ solvent concentration and antibiotic streptomycin sulphate $(10 \mu \mathrm{g} / \mathrm{ml})$ against bacterial species tested by Disc Diffusion

$$
\text { assay }
$$

\begin{tabular}{|c|c|c|c|c|}
\hline Test organism & \multicolumn{4}{|c|}{ Diameter of zone of inhibition(mm) } \\
\hline Gram positive & EAE & DCME & MEE & SMS \\
\hline Bacillus subtilis & 4 & 0.00 & 0.00 & \\
\hline Streptococcus & 9 & 0.00 & 2 & \\
\hline Staphylococcus aureus & 23 & 0.00 & 4 & 15 \\
\hline \multicolumn{5}{|l|}{ Gram Negative } \\
\hline Escherichia coli & 20 & 0.00 & 2 & 18 \\
\hline Klebsiella pneumonia & 18 & 0.00 & 0.00 & 0. \\
\hline
\end{tabular}


$\mathrm{EAE}=$ Ethyl acetate extract

DCME $=$ Dichloromethane extract

MEE=Methanol extract; SMS = Streptomycin sulphate

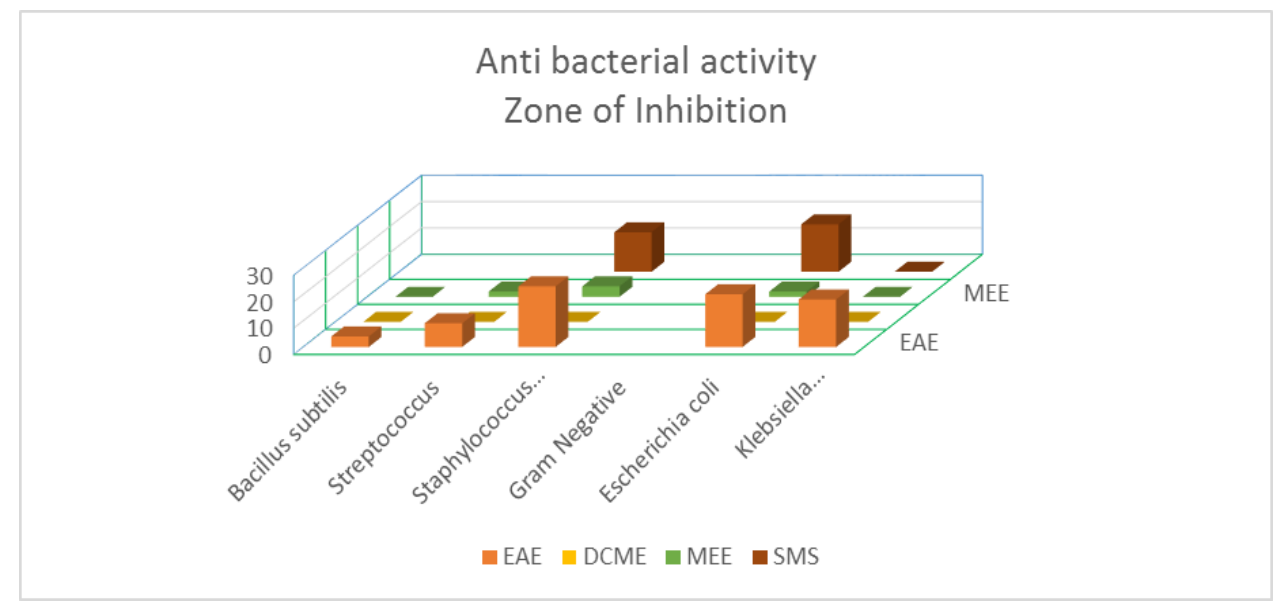

TABLE 2: Antifungal activity of crude organic solvent extracts of knoxia corymbosa $-5 \mu 1 / 50 \mu 1$ solvent concentration and fungicide Nystatin against fungal species tested by Disc Diffusion assay

\begin{tabular}{|l|l|l|l|}
\hline Test organism & Diameter of zone of inhibition(mm) & NEE \\
\hline & EEE & 0.00 & \\
\hline Candida albicans & 0.00 & 0.00 & 20 \\
\hline Aspergillus niger & 23 & & \\
\hline
\end{tabular}

$\mathrm{EAE}=$ Ethyl acetate extract

MEE $=$ Methane extract

NT $=$ Fungicide Nystatin
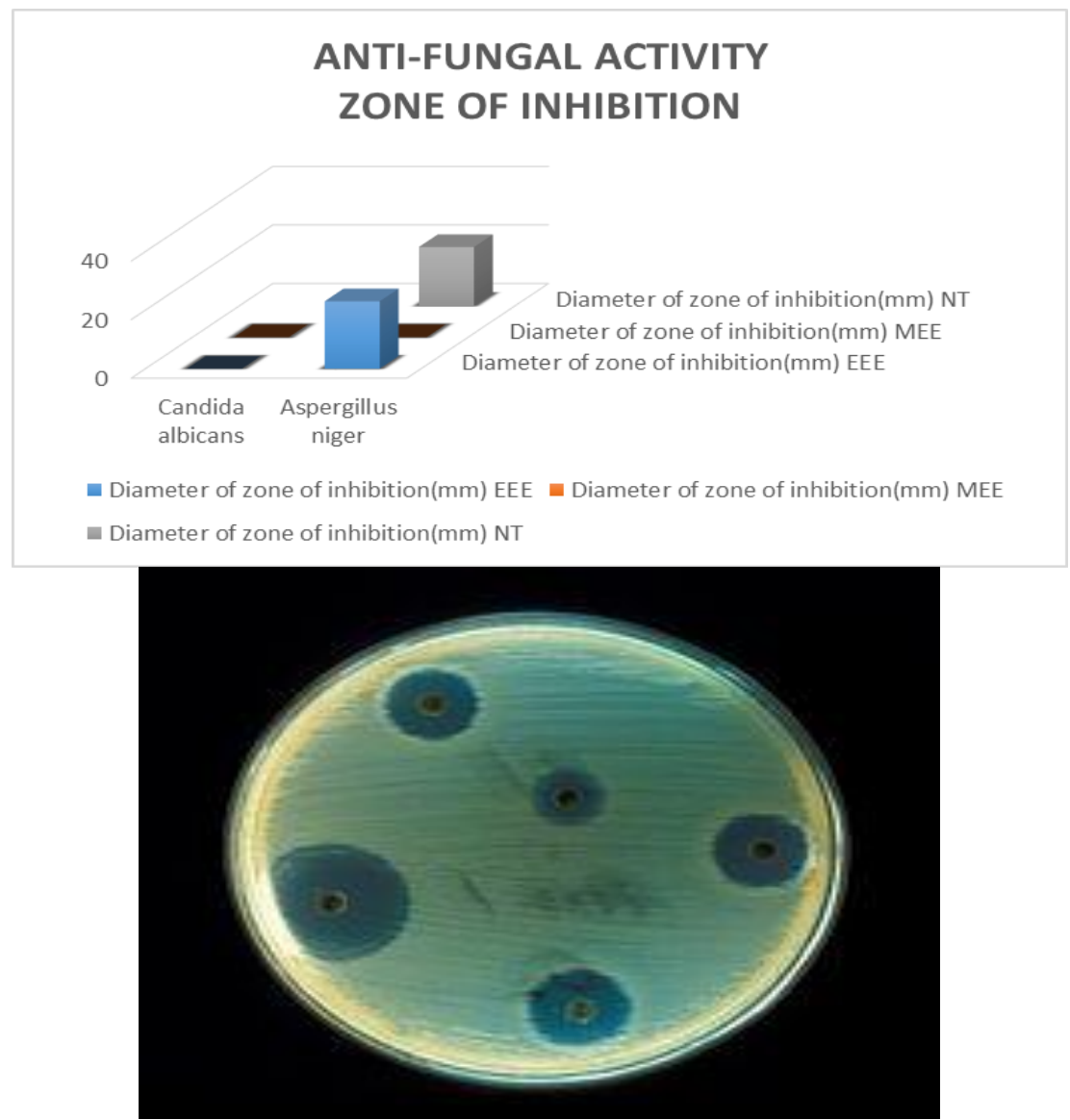


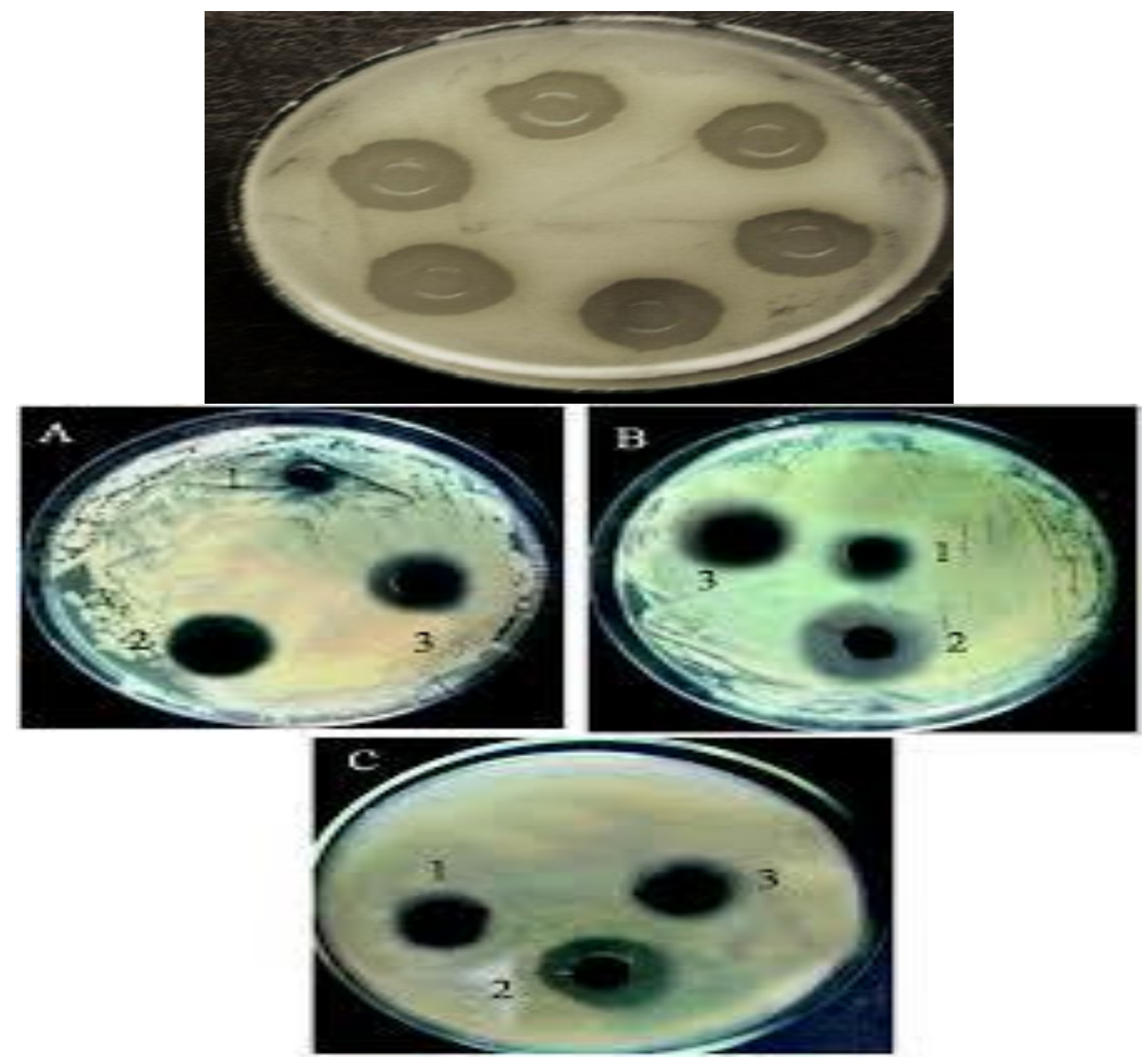

IV. Conclusion

Plants are the natural sources to promote health, from the present study it can be concluded that the antibacterial activity of Knoxia corymbosa leaf extracts of Ethyl acetate, dichloromethane, and methanol extracts are effective against various gram positive organisms and gram negative organisms and antifungal activity against fungal organism. Extensive studies are to be carried out to find out which of the chemical constituent might be responsible for antibacterial activity and antifungal activity. Finally Knoxia corymbosa may be useful to various other diseases also; further investigation need to be done for this.

\section{Acknowledgments}

The authors Dr. R.Mrutyunjaya Rao and K.Ramakrishna are grateful to University Grants Commission, New Delhi for awarding Major Research Project.

\section{References}

[1]. Studies on the Chemical Constituents of Knoxia Corymbosa YB Wang et al. Yao Xue Xue Bao 39 (6), $439-441 .(6) 2004$.

[2]. Y. B. Wang, J. X. Pu, H. Y. Ren et al., "New acetylated flavonolglycosides from Knoxia corymbosa," Chinese Chemical Letters, vol. 14, no. 12, pp. 1268-1270, 200

[3]. Das S, Bhattacharya AK (1969). Chemical investigations on Knoxia corymbosa. J. Indian Chem. Soc. 1: $301-02$

[4]. Je-Chiuan Ye1, Wei-Chun Chang 2, Dennis Jine-Yuan Hsieh3 and Meen-Woon Hsiao Extraction and analysis of $\beta$-sitosterol in HerbalMedicines

Journal of Medicinal Plants Research Vol. 4(7), pp. 522-527, 4 April, 2010

[5]. Feng Zhao, Shuai Zhao, Jing-Tian Han, Yuan-Fang Wang, Ya-Nan Wang, Chun- Hua Antiviral anthraquinones from the roots of Knoxia valerianoides Photochemistry Letters Volume 11, March 2015, Pages 57-60.

[6]. Forbes AB, Sahm FD, Weissfeld SA (2007). Mycology. In: Bailey \& Scott's Diagnostic Microbiology. Mosby,Elsevier, St. Louis. pp. $696-697$.

[7]. Herborn, J.B. 1973. Phytochemical methods, A Guide to Modern Techniques of Plant Analysis, pp. 5-11, 2ndedition, Hall, New York.

[8]. Kirtikar, K.R., and Basu, B.D., 1993. Indian Medicinal Plants, 2nd ed., Vol. I, Dehradun: International Book Publisher; p. 641. 